\title{
Association of Congenital Diaphragmatic Hernia in a Baby with Patau Syndrome
}

\author{
Vithanage ND ${ }^{1}$, Hapuarachchi GK², Gomaz K², Munasingha TM ${ }^{1}$
}

\section{Introduction}

Patausyndrome or trisomy 13 is one of the most severe forms of trisomyand the affected children are usually viable for short duration. Median survival is reported as 7-10 days. Gestational age is the main predictor of mortality.1Frequent clinical manifestations include neural tube defects, brain anomalies; specially holoprocencephaly, micropthalmia, cleft lip and palate, congenital heart disease, overlapping and flexion of fingers, polydactyly and Rocker bottom feet. ${ }^{1}$

There are only very few documented associations of Patau syndrome with congenital diaphragmatic hernia. ${ }^{2}$ Here we report a case of a child with Patau syndrome associated with diaphragmatic hernia.

\section{Case report}

A baby boy weighing $2500 \mathrm{~g}$ was delivered by an emergency LSCS at 34 weeksdue to major degree placenta previa with bleeding. Parents were non consanguineous and healthy. Baby was resuscitated at birth and $1 \mathrm{~min}$ APGAR score was 6 and 5 min APGAR score was 9. Baby was detected to have several congenital anomalies at birth including low set ears, wide anterior fontanella, bilateral cleft lip andpalate, bilateral overlapping flexed fingers, left side talipesequinovarus deformity and bilateral Rocker bottom feet. His abdomen was scaphoid and heart sounds were best heard in the right side of the precordium with prominent systolic murmur. Baby was admitted to Neonatal Intensive Care Unit. Due to persistent respiratory distress with metabolic acidosis, he was intubated and ventilated. Chest xray revealed a left sided congenital diaphragmatic hernia. An echocardiogram was done and it revealed moderate size Ostiumsecondum Atrial Septum Defect.

1. University Paediatric Unit, Teaching Hospital Karapitiya

2.Neonatal Intensive Care Unit, Teaching Hospital Mahamodara

Corresponding Author: ND Vithanage. Email:nimanthadvg@gmail.com
Considering the presence of congenital anomalies and the poor prognosisof the condition, conservative management was planned after discussing with the paediatric surgical team and the parents. Baby succumbed to death on day 16 of life.

Karyotyping report obtained in few weeks after the death confirmed the diagnosis of Patau syndrome.

\section{Discussion}

Patausyndrome results mainly due to non dys-junction and incidence increases with advanced maternal age.2Babies with Patau syndrome usually presents with a low APGAR score at birth. Clinical manifestations detected in this child were micropthalmia, cleft lip and palate, congenital heart disease, overlapping and flexion of fingers and Rocker bottom feet. Unlike many babies with Patau syndrome that are small for their gestational age, this baby was grown adequately for his age.

Diaphragmatic hernia (DH) is a communication between the thoracic cavity and abdominal cavity with possibility of abdominal contents in the thorax. The prognosis and severity depends on the type of hernia and associated anomalies. Associated pulmonary hypoplasia is the major limiting factorfor survival. The commonest type is Bochdalek type ( $90 \%$ of Congenital $\mathrm{DH}$ ) in which defect is in the postero-lateral aspect of the diaphragm. ${ }^{3}$

The incidence of $\mathrm{DH}$ is $1: 2000$ to $1: 5000$ in live births. Female to Male ratio is 2:1 and most defects occur in the left side (85\%)3. Associated anomalies include brain anomalies, Oesophageal atresia, Omphalocoele, Cardiovascular anomalies. $\mathrm{DH}$ is a recognized anomaly in many chromosomal syndromes.10\% of diaphragmatic Hernia is associated with chromosomal anomalies.3The most common are trisomy 18 and isochromosome12p (Pallister Killian syndrome).

Trisomy 21 , Turner syndrome,Cornelia de Lange syndrome, Denys Drash syndrome, Donnai Barrow syndrome, Fryns syndrome, spondylocoastaldysostosis, Meachan syndrome are other associated syndromes.4Even though there is a recognized association between Trisomy 13 and congenital diaphragmatic

https://orcid.org/0000-0002-1209-9402 
hernia, it is a rare occurrence. There are only few case reports available in literature.

Ina similarcasereportpublished in 2015 , the baby had undergone corrective surgery for diaphragmatic hernia but had succumbed to death later. ${ }^{2}$ We opted for conservative management in this child considering the known poor prognosis of the condition with associated multiple anomalies.

\section{Reference}

1. Meyer RE,Liu G, Gilboa SM, et al. Survival of Children with Trisomy 13 and Trisomy 18: A Multi-State Population-Based Study. American Journal of MedicalGenetics A. 2016 Apr; 170(4): 825-837.

2. Jain A, Kumar P, Jindal A,SarinYK. Congenital Diaphragmatic Hernia in a Case of Patau Syndrome: A Rare Association, Journal of Neonatal Surgery 2015 Apr-Jun; 4(2): 20

3. Kliegman RM, Stanton BF,Geme JWS,Schor NF,Behrman RE. Diaphragmatic Hernia,Nelson Text Book of Paediatrics,2016;20th edition:862-864

4. Joshi, M., Khandelwal, S., Zade, P.S., \& Prajapati, R.M. (2012). Congenital Diaphragmatic Hernia and Associated Anomalies. 